\title{
PREDICTION OF PLASTIC STRAIN FOR RECRYSTALLISATION DURING INVESTMENT CASTING OF SINGLE CRYSTAL SUPERALLOYS
}

\author{
C. Panwisawas ${ }^{1}$, H. Mathur ${ }^{2}$, J.-C. Gebelin ${ }^{1}$, \\ D.C. Putman ${ }^{3}$, P. Withey ${ }^{3}$, N. Warnken ${ }^{1}$, C.M.F. Rae ${ }^{2}$ and R.C. Reed ${ }^{1}$ \\ ${ }^{1}$ Department of Metallurgy and Materials, \\ University of Birmingham, Edgbaston, Birmingham B15 2TT, UK \\ ${ }^{2}$ Department of Materials Science and Metallurgy, \\ University of Cambridge, Pembroke Street, Cambridge CB2 3QZ, UK \\ ${ }^{3}$ Rolls-Royce plc., P.O. Box 31, Derby DE24 8BJ, UK
}

Keywords: Modelling, investment casting, recrystallisation, plastic strain accumulation

\begin{abstract}
Castings for single crystal aerofoils can be prone to recrystallisation during solution heat treatment; however quantitative information concerning the factors causing this phenomenon is lacking. In this paper, mathematical modelling and targeted experimentation are used to deduce the levels of localised plastic strain needed for recrystallisation to occur. The influences of differential thermal contraction against the shell, specimen geometry and stress concentration factor are quantified. The model predicts that the induced strain in the metal increased with the ceramic shell thickness, and in some geometries, with the solidification height. Negligible plastic strains were predicted in a solid casting with no stress concentration features. However, as the geometry became more complex by reducing the casting cross-section, by the insertion of a core and introduction of stress concentration features, the induced plastic strains increased significantly. The predicted plastic strain for recrystallisation in a cored casting was in good agreement with experimental critical strain data. The model provides the foundation for a systems-based approach which enables recrystallisation to be predicted and thus avoided, prior to its occurrence in the foundry.
\end{abstract}

\section{Introduction}

It is well known that turbine blades for gas turbine applications are investment cast, often into single crystal form. But much less appreciated is that during processing, deformation is induced in the nickel-based superalloy during cooling; this is due to differential thermal contraction of the ceramic shell, core and the metal arising primarily from their differing thermal expansion coefficients [1]. In the foundry, this effect has some practical ramifica- tions. First, account needs to be taken of the shrinkages [2] which occur - for example, the final casting will not exhibit the same dimensions as the wax model. Second, plastic strains can be produced which are large enough to induce recrystallisation during subsequent solutioning heat treatment. Particularly for components cast in single crystal form, the occurrence of recrystallisation cannot be tolerated - the associated high angle grain boundaries degrade the creep $[3,4]$ and fatigue $[5,6]$ properties significantly. Work has been done to study the recrystallisation behaviour of single crystal superalloys under the influence of different annealing conditions and microstructural features $[1,5,6,7,8,9]$. However, from the processing perspective, very little attention has been given to developing a systematic approach to controlling this problem.

This paper is concerned with the mathematical modelling of investment casting, with particular emphasis on thermal-mechanical effects so that processing-induced plasticity can be predicted and rationalised. The overarching goal is to build a physics-based tool for the prediction of recrystallisation during the processing of single crystal parts. Traditionally, the avoidance of recrystallisation has been dealt with in a rather empirical way, with reliance placed on existing casting practice, experience and rules of thumb. Mathematical modelling represents a method by which the physical effects causing recrystallisation can be anticipated, which is obviously advantageous. Such modelling might be used for the optimisation of processing conditions, so that the likelihood of recrystallisation can be reduced. If sufficiently robust, it might also be used during the early stages of design process to influence the geometry chosen for the turbine blade - as part of a systems-based approach to component design. 


\section{Methods}

Modelling approach

For the purposes of the present work, and in particular to simplify the modelling and experimentation validation, a simplified geometry was considered adequate. This was designed to represent an analogue of a turbine blade aerofoil, of approximately comparable size and containing flanges to simulate the mechanical constraints provided by platforms and shrouds. Figure 1 illustrates the details of the

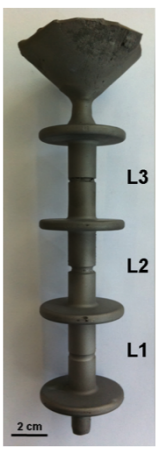

(a)

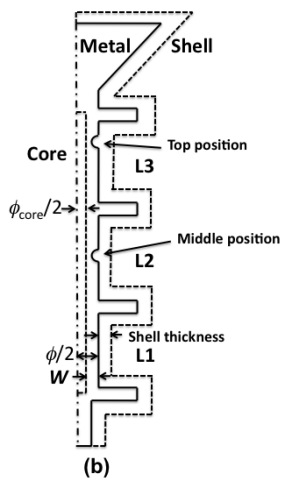

Figure 1: Casting geometry of turbine blade analogue testpiece ("bobbin" geometry): (a) real casting with all notches in the middle position and (b) schematic illustration of the geometry, where $\phi_{\text {core }}, \phi$ and $W$ are core diameter, gauge diameter and wall thickness, respectively

testpiece analysed, which has been christened the "bobbin" geometry. Between the three platforms/shrouds flanges of thickness $5 \mathrm{~mm}$, and fillet radii of $2 \mathrm{~mm}$ were introduced consistent with a stress concentration factor of 1.80 . The three gauge lengths of diameter $15 \mathrm{~mm}$ are identified according to the notation $L_{1}, L_{2}$ and $L_{3}$, with $L_{1}$ and $L_{3}$ being the first and last to solidify, respectively, during the casting. In some cases - in order to introduce greater complexity - further stress concentration features of known factors $K_{t}$ were introduced into the gauge lengths. In some further instances, a ceramic core was used to facilitate the casting of hollow testpieces of wall thickness as small as $1.5 \mathrm{~mm}$. The details of the various geometries considered are summarised in Table 1. The nominal thickness of the shell was $5.5 \mathrm{~mm}$.

The finite element method was employed for the modelling, with use being made of the ProCAST software [10]. Temperature dependent material parameters and isotropic mechanical behaviour in as-cast condition were assumed, consistent with the single crystal superalloy
CMSX-4, which was used for the validation studies. Thus, the following thermal and mechanical properties of CMSX4 were employed: density, specific heat capacity, thermal conductivity, yield stress, ultimate yield strength, hardening exponent, thermal expansion coefficient, Young's modulus and Poisson's ratio, taken in the $\langle 001\rangle$ solidification direction. The stresses and strains, especially plastic strains, are of primary interest here; since radial symmetry was present in all cases, it proved sufficient to model only a 30 degree section of the components for the mechanical part of the calculation. For the superalloy, an elastic-plastic formulation has been employed assuming an isotropic yield criterion. In the modelling, effective (accumulated) plastic strain is approximated by $\epsilon^{\mathrm{pl}}$. The relationship between stress, $\sigma$, and $\epsilon^{\mathrm{pl}}$ which describes the hardening mechanism is defined by

$$
\sigma=\sigma_{\infty}+\left(\sigma_{\mathrm{y}}-\sigma_{\infty}\right) \exp \left\{-H \epsilon^{\mathrm{pl}}\right\}
$$

where $\sigma_{\infty}, \sigma_{\mathrm{y}}$ and $H$ are ultimate yield stress, yield strength and hardening exponent, respectively. For the superalloy, model parameters were adopted from [3]. For the shell and core, representative values for alumina- and silica-based shell materials adapted from [11] were used.

\section{Validation studies - investment casting}

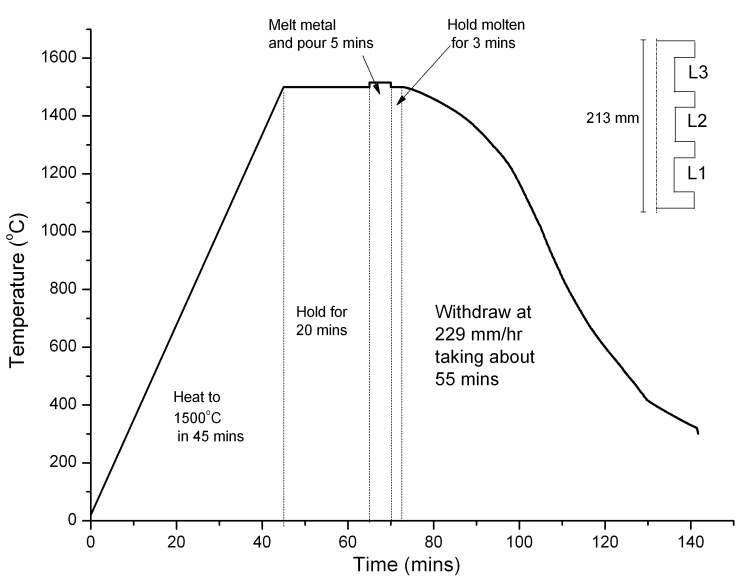

Figure 2: Heating cycle used during the investment casting trials.

To assist with model validation, some of the geometries identified in Table 1 were fabricated from the CMSX-4 single crystal superalloy. A semi-industrial scale investment single-shot casting facility at University of Birmingham 
Table 1: Details of the bobbin castings which were modelled; those chosen for experimental casting are labelled by ${ }^{\dagger}$.

\begin{tabular}{|c|c|c|c|c|c|c|c|c|}
\hline \multirow[t]{2}{*}{ No. } & \multirow[t]{2}{*}{ Label } & \multirow{2}{*}{$\begin{array}{c}\text { Gauge diameter }(\phi) \\
(\mathrm{mm})\end{array}$} & \multirow{2}{*}{$\begin{array}{c}\text { Notch } \\
\text { position }\end{array}$} & \multicolumn{3}{|c|}{$K_{t}$} & \multirow{2}{*}{$\begin{array}{l}\text { Wall thickness }(W) \\
(\mathrm{mm})\end{array}$} & \multirow{2}{*}{$\begin{array}{l}\text { Core diameter }\left(\phi_{\text {core }}\right) \\
(\mathrm{mm})\end{array}$} \\
\hline & & & & $L_{1}$ & $L_{2}$ & $L_{3}$ & & \\
\hline 1 & $\mathrm{SB} 15^{\dagger}$ & 15 & - & - & - & - & - & - \\
\hline 2 & SB9 & 9 & - & - & - & - & - & - \\
\hline 3 & $\operatorname{MSB} 15^{\dagger}$ & 15 & Middle & 1.6 & 2.0 & 2.6 & - & - \\
\hline 4 & TSB15 & 15 & Top & 1.6 & 2.0 & 2.6 & - & - \\
\hline 5 & MSB9 & 9 & Middle & 1.6 & 2.0 & 2.6 & - & - \\
\hline 6 & $\mathrm{CB} 1.5^{\dagger}$ & 15 & - & - & - & - & 1.5 & 12 \\
\hline 7 & TSB9 & 9 & Top & 1.6 & 2.0 & 2.6 & - & - \\
\hline 8 & MCB & 15 & Middle & 1.6 & 2.0 & 2.6 & $1.5 \leq W \leq 3.5$ & 9 \\
\hline 9 & TCB & 15 & Top & 1.6 & 2.0 & 2.6 & $1.5 \leq W \leq 3.5$ & 9 \\
\hline 10 & MSB-1 & 15 & Middle & 1.6 & 1.6 & 1.6 & - & - \\
\hline 11 & MSB-2 & 15 & Middle & 2.0 & 2.0 & 2.0 & - & - \\
\hline 12 & MSB- $3^{\dagger}$ & 15 & Middle & 2.6 & 2.6 & 2.6 & - & - \\
\hline 13 & TSB-1 & 15 & Top & 1.6 & 1.6 & 1.6 & - & - \\
\hline 14 & TSB-2 & 15 & Top & 2.0 & 2.0 & 2.0 & - & - \\
\hline 15 & TSB-3 & 15 & Top & 2.6 & 2.6 & 2.6 & - & - \\
\hline 16 & CB3.0 & 15 & - & - & - & - & 3.0 & 9 \\
\hline
\end{tabular}

was employed. Moulds were prepared using wax assembly, ceramic processing and steam-autoclave dewaxing methods, following standard procedures.

The casting cycle followed is shown Figure 2. The molten metal was poured under vacuum conditions at $1500^{\circ} \mathrm{C}$ into the mould, and withdrawn thereafter at $229 \mathrm{~mm} / \mathrm{hr}$; when all of the mould had passed the baffle, cooling was allowed to proceed in air. Some of the castings were instrumented using $\mathrm{Rh} / \mathrm{Pt}$ Type B thermocouples, which have measurement capability up to $1750^{\circ} \mathrm{C}$, with use being made of alumina sheaths of $4 \mathrm{~mm}$ outside diameter, $2 \mathrm{~mm}$ inside diameter and $15 \mathrm{~mm}$ length. All castings received the standard CMSX-4 solution heat treatment, which has a final solutioning step of $1315^{\circ} \mathrm{C} / 6 \mathrm{hrs}[1]$.

$\underline{\text { Transmission electron microscopy }}$

Transmission electron microscopy (TEM) was used to study the deformation induced during the investment casting process. As cast bars of the CMSX-4 superalloy were used for this purpose. For sample preparation, discs of $\sim 3$ $\mathrm{mm}$ diameter and $0.2-0.3 \mathrm{~mm}$ thickness were subjected to twin-jet electropolishing with $10 \%$ perchloric acid solution in methanol; $20.5 \mathrm{~V}$ and $-5^{\circ} \mathrm{C}$ were the working conditions. A JEOL 200CX TEM was used at an accelerating voltage of $200 \mathrm{kV}$ for bright field imaging of the deformed microstructures.
Mechanical testing - critical plastic strain for recrystallisation

Deformation testing in compression of as-cast CMSX4 was carried out at different temperatures in order to evaluate the critical straining conditions necessary for recrystallisation. Samples for this purpose were sliced from as-cast bars, such that their external convex surfaces were consistent with an as-cast surface finish; they were of $10 \mathrm{~mm}$ diameter and $12 \mathrm{~mm}$ length. At temperature these were compressed uniaxially parallel to $\langle 001\rangle$ at $0.2 \% / \mathrm{min}$. The strained samples were subsequently subjected to the standard solution heat treatment for CMSX-4. All samples were sectioned longitudinally along $\langle 001\rangle$ for examination.

\section{Results}

In this section our results are summarised as follows. First, some basic considerations relevant to the problem are discussed; results from a basic one-dimensional model are given and its predictions are compared with results from TEM. Next, results from (i) the thermal and (ii) thermal-mechanical finite element modelling are presented. There follows a sensitivity analysis which explores the effects of the important processing parameters. Finally, the predictions are compared with the results from our experimental studies. 
Preliminary Considerations

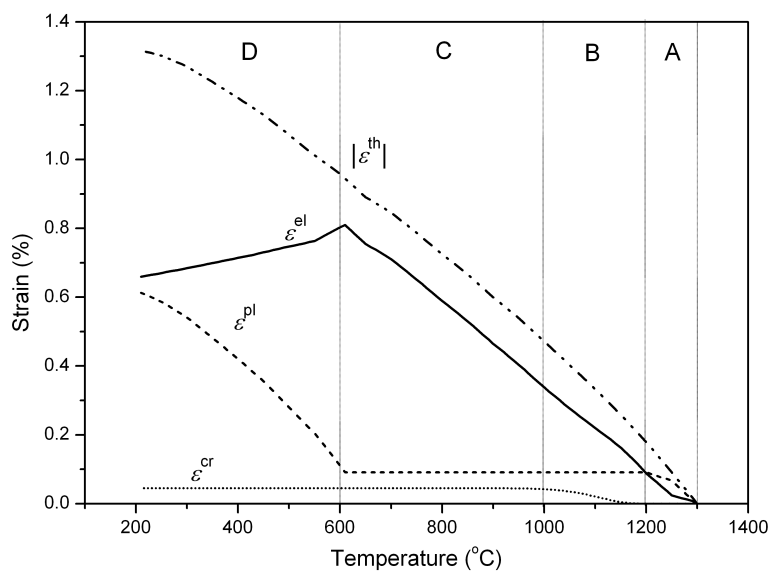

Figure 3: Strain evolution during cooling from $1300^{\circ} \mathrm{C}$, as predicted by the $1 \mathrm{D}$ modelling. The terms $\epsilon^{\text {th }}, \epsilon^{\mathrm{el}}, \epsilon^{\mathrm{pl}}$ and $\epsilon^{\mathrm{cr}}$ are the magnitudes of the total thermal strain, elastic strain, plastic strain and creep strain, respectively.

Consider the situation of a solid cylinder of CMSX-4 held within a mould assumed to be totally rigid; this simple test case can then be modelled in 1D using an elasto-viscoplastic material law under the assumption of isotropic elasticity in one dimension. The decomposition of the total strain into the sum of each strain components was assumed The calculation detail can be found in [12]. The cooling rate is assumed to be uniform at $229 \mathrm{~mm} / \mathrm{hr}$, consistent with the data of Figure 2. The results, which are shown in Figure 3, indicate that about $0.1 \%$ plastic strain is induced at temperatures in excess of $1200^{\circ} \mathrm{C}$, see zone A which is marked on the figure. On further cooling, creep is found to play a role in zone B between $1200^{\circ} \mathrm{C}$ and $1000^{\circ} \mathrm{C}$. Further plastic strain is induced only when the temperature falls to $600^{\circ} \mathrm{C}$, building up substantially thereafter - zone D. Within zone $\mathrm{C}$ between $1000^{\circ} \mathrm{C}$ and $600^{\circ} \mathrm{C}$, the inelastic strains do not increase at all. These calculations indicate that the plasticity which is the cause of recrystallisation is likely to be induced soon after solidification is completed, at temperatures in excess of $1000^{\circ} \mathrm{C}$.

To further investigate these predictions the microstructure of CMSX-4 in the as-cast condition was examined using TEM. The interdendritic regions showed an appreciable dislocation density, whereas the dendritic regions appeared relatively dislocation-free, see Figure 4(a) and 4(b). Dislocations were primarily at the $\gamma / \gamma^{\prime}$ interface forming loops around the precipitates.
To place these observations into context, deformation in as-cast samples strained at various temperatures were studied. Between $20^{\circ} \mathrm{C}$ and $550^{\circ} \mathrm{C}$ shearing by dislocations along the $\{111\}\langle 110\rangle$ slip systems was the primary deformation mechanism, with dislocations dipoles, loops and pairs in the $\gamma^{\prime}$, Figure 4(c). However, with deformation at $750^{\circ} \mathrm{C}$ stacking faults were also observed within the $\gamma^{\prime}$, Figure 4(d); these form due to the activation of $\{111\}\langle 112\rangle$ slip systems. At higher temperatures of $1050^{\circ} \mathrm{C}$ and $1200^{\circ} \mathrm{C}$, dislocation networks form at the $\gamma / \gamma^{\prime}$ interface, Figure 4(e) and 4(f), leaving both $\gamma$ and $\gamma^{\prime}$ relatively dislocation-free.

The dislocation structure within the as-cast microstructure is rarely reported and it is significant that a high dislocation density is observed. Solution heat treatment would dissolve the $\gamma^{\prime}$ allowing the loops to annihilate to give the more familiar dislocation-free microstructure. The simple geometry of the bar experiences the lowest possible stresses during casting, yet clearly undergoes deformation at the yield stress appropriate to the deformation temperature. Comparison of the microstructures in Figure 4 shows that the as-cast microstructures of Figures 4(a) and 4(b) most nearly resemble the higher temperature deformation of Figures 4(e) and 4(f), evidenced by the absence of stacking faults, dislocation dipoles and loops within the $\gamma^{\prime}$. Differences in the dislocation density between the dendritic and interdendritic areas suggest plasticity close to the $\gamma^{\prime}$ solvus temperature as, in a highly segregated microstructure, the dendritic area would be the last to form the $\gamma^{\prime}$. This is consistent with the predictions from the model that most of the deformation occurs between $1200^{\circ} \mathrm{C}$ and $1300^{\circ} \mathrm{C}$, as depicted in Figure 3. There is no evidence of the plastic deformation below $600^{\circ} \mathrm{C}$, and the necessary stresses for yield at $600^{\circ} \mathrm{C}$ are probably above the fracture stress of the ceramic shell.

\section{Thermal model}

Thermocouple measurements were made at the locations $L_{1}$ and $L_{2}$ during the casting of the bobbin testpiece SB15 of Table 1. Figure 5 compares the thermocouple readings with the results of the modelling. As expected, given the location of the thermocouples, the readings from $L_{2}$ are consistently higher than those from $L_{1}$ at any given time; a maximum difference of up to $120^{\circ} \mathrm{C}$ was measured. The model predictions are in good agreement with the experimental results between approximately $1515^{\circ} \mathrm{C}$ and $1000^{\circ} \mathrm{C}$.

The important temperature range for this study is between $1300^{\circ} \mathrm{C}$ and $1000^{\circ} \mathrm{C}$, since strain accumulation occurs only below the solidus temperature of the alloy, which 

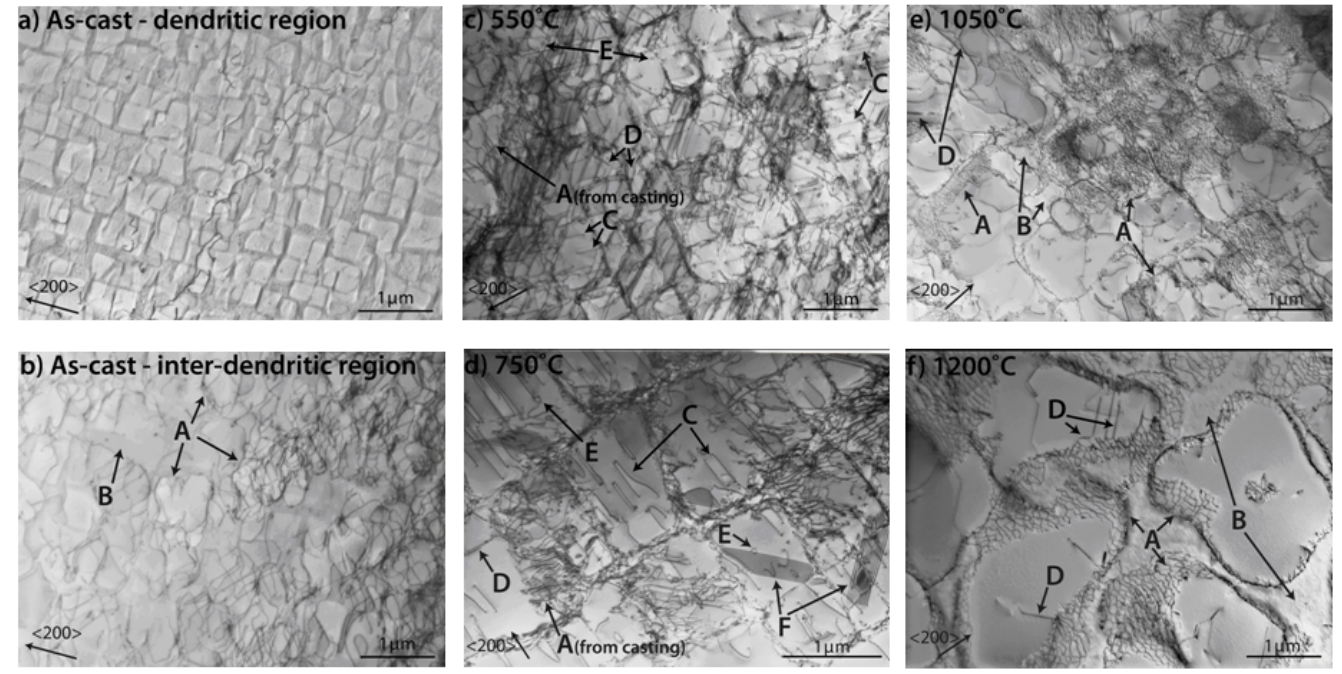

Figure 4: Dislocation structures in as-cast CMSX 4: (a) dendritic region in a bar; (b) interdendritic region in a bar; (c) tensile plastic strain of $1.51 \%$ at $550^{\circ} \mathrm{C}$; (d) tensile plastic strain of $1.45 \%$ at $750^{\circ} \mathrm{C}$; (e) tensile plastic strain of $1.85 \%$ at $1050^{\circ} \mathrm{C}$; (d) tensile plastic strain of $1.30 \%$ at $1200^{\circ} \mathrm{C}$. A: dislocations at $\gamma / \gamma^{\prime}$ interface, B: dislocation-free $\gamma$, C: dislocation dipoles, D: dislocation pairs, E: dislocation loops, F: stacking faults. The mottled appearance within $\gamma$ in (e) and (f) is due to reprecipitation of $\gamma^{\prime}$ during cooling. The TEM foil normal is $\langle 001\rangle$ - bright field images with $\vec{g}=\{200\}$.

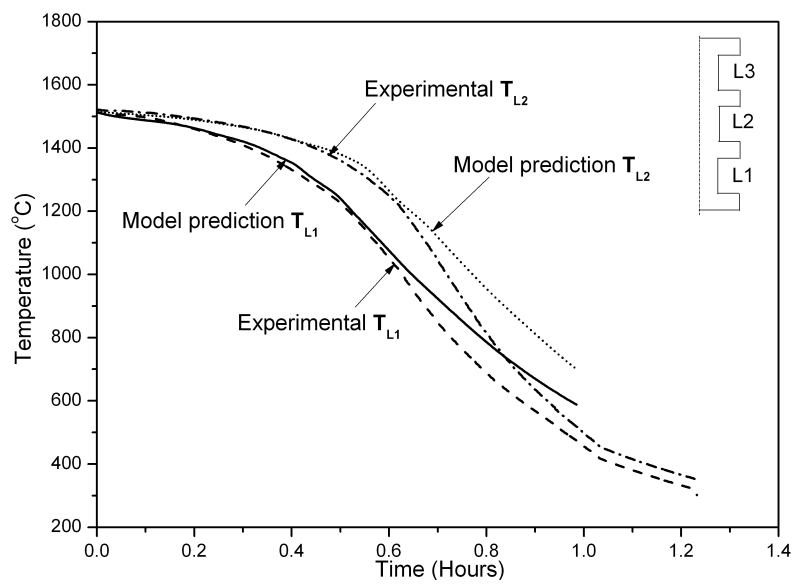

Figure 5: Comparison between predicted thermal fields and thermocouple measurements during the casting of SB15. is about $1330^{\circ} \mathrm{C}$; this is consistent with the predictions in Figure 3. Below $1000^{\circ} \mathrm{C}$, the model underestimates the cooling rates somewhat, due to the rather complicated heat transfer effects which are not accounted for perfectly. However, as it has been seen that only temperatures above $1000^{\circ} \mathrm{C}$ are significant for recrystallisation (Figures 3 and 4 ), the results in Figure 5 demonstrate that the thermal characteristics of the furnace used are captured sufficiently well.

\section{Thermal-Mechanical Model}

Thermal-mechanical modelling was carried out using the ProCAST software, specifically to explore the effects of geometry, stress concentration features, shell thickness and shell type.

In summarising the results, use will be made of the notation of Table 1.

Figure 6 illustrates the significant effects of shell thickness and stress concentration factor, which have been found for the solid testpieces MSB-1 to TSB-3 of Table 1. One sees first that there is a substantial effect due to the thickness of the shell; greater thicknesses have the capacity to increase the accumulated plastic strains markedly. The 


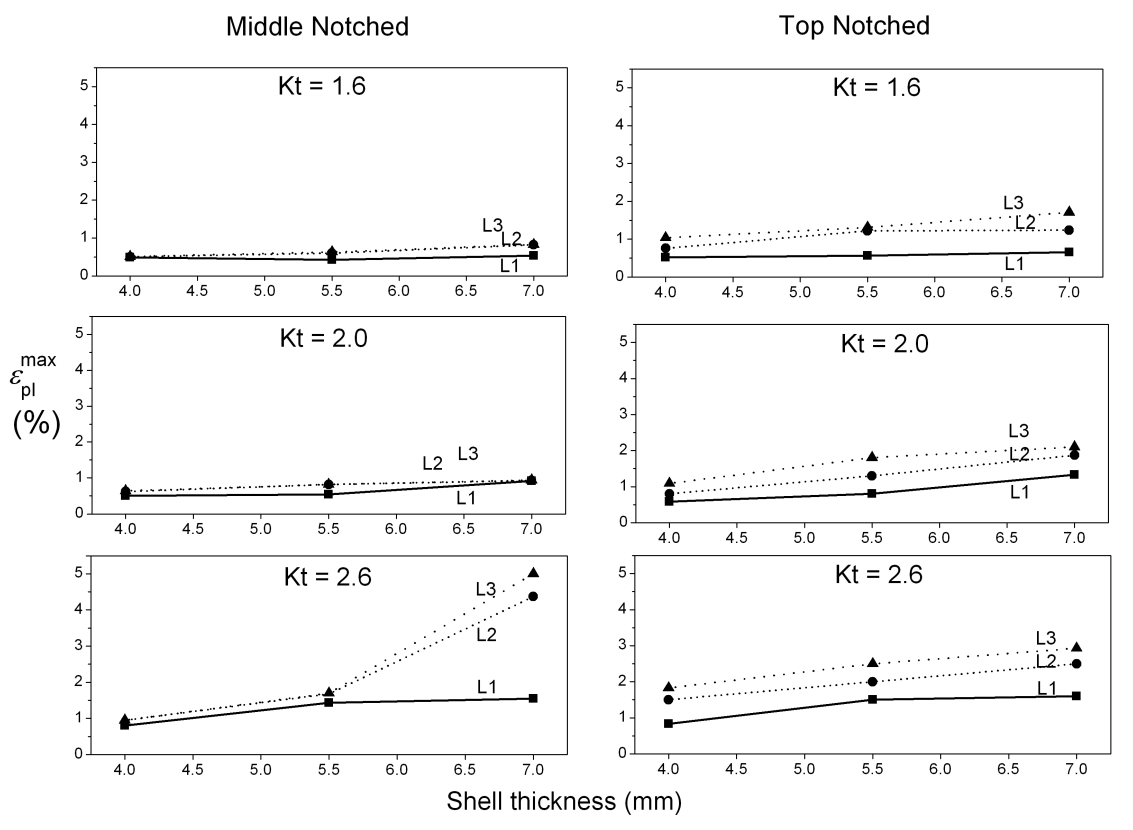

Figure 6: Variation of effective plastic strain accumulation with shell thickness and stress concentration factors in different locations.

effect is greatest when the stress concentration factor $K_{t}$ is as high as 2.6; the plastic strains produced by $K_{t}$ values of 1.6 and 2.0 were found to be approximately the same and not strongly influenced by shell thickness.

The plastic strains predicted by the modelling were found to be consistently higher for the $L_{3}$ location than $L_{1}$, and in general in the order $L_{3}>L_{2}>L_{1}$. This is logical as the lower part of the casting solidifies first and thereafter is always at a lower temperature than positions lying above it - these get strained to a greater extent due to their higher temperatures with concomitantly lower yield stresses. The maximum plastic strain induced was also affected by the location of the notch, e.g. whether it was placed at the very middle of the gauge or alternatively directly under the flange, see Figure 1. Higher plastic strains were generally seen in the latter cases, and this appeared to be an effect of the overlap of stresses at the concentration features around the fillet radii under the flanges with that of the machined notches.

In addition to the above, a sensitivity analysis for plastic strain accumulation was carried out to explore the effects of shell material and withdrawal rates. Two distinct shell systems were studied: an alumina-based one (referred to here as Shell1) and a silica-based one (Shell2). Thermal
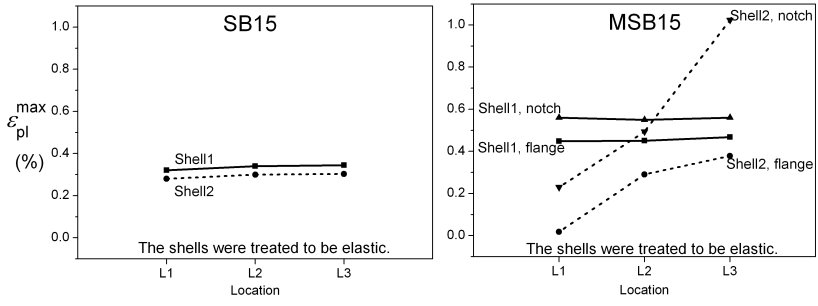

Figure 7: Variation of effective plastic strain with different shell materials, for SB15 and MSB15 bobbin testpieces.

expansion coefficients and Young's moduli have been assumed to be linear functions of temperature, and given the materials used Shell1 is appreciably stiffer than Shell2; consequently, more plastic strain might be anticipated within the metal cast in Shell1 than in Shell2. Calculations were carried out for the SB15 and MSB15 geometries, see Figure 7. The plastic strain induced in the unnotched bobbin SB15 was small and not appreciably influenced by shell type; moreover, the plastic strain was uniformily distributed along the casting. For the notched testpiece 
MSB15, the strain was concentrated strongly around the notch, and in particular for Shell2 it showed again the tendency $L_{3}>L_{2}>L_{1}$. For Shell1 the plastic strain did not vary strongly from gauge length to gauge length. Withdrawal rate was also found to exhibit a significant

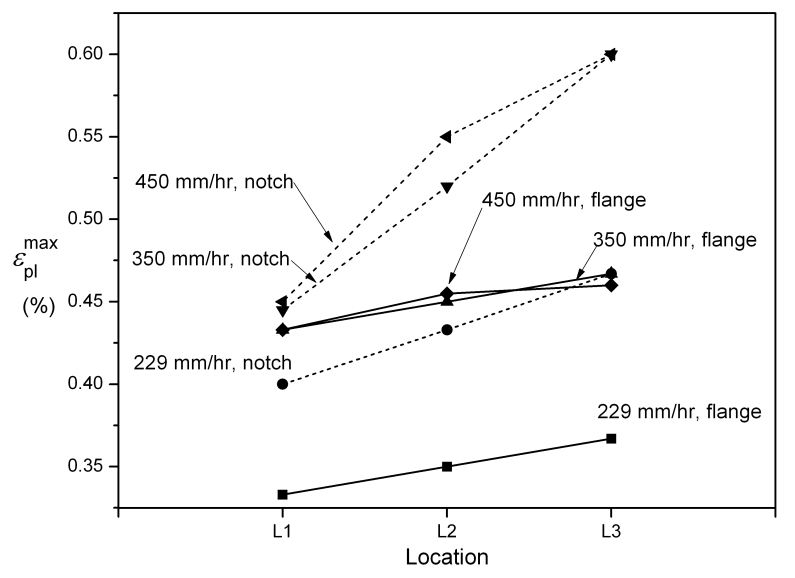

Figure 8: Variation of effective plastic strain with withdrawal rates for the MSB15 bobbin.

effect on the level of plastic strain accumulated. Slower withdrawal rates lead to slower cooling rates and hence lower strain rates for deformation. Generally, this leads to lower plastic strains. Figure 8 illustrates the quantitative data associated with this effect. More deformation was found around the notches of MSB15 than under the flange features.

To summarise, all castings listed in Table 1 were modelled to examine the cumulative effect of casting crosssection, strength of stress concentration factor, its location and the presence of a core. Figure 9 plots the maximum plastic strain generated in the different castings and confirms that there is a strong influence of casting geometry. In the solid castings the induced strain was low and approximately constant irrespective of the gauge diameter and even in the solid castings with the stress concentration features the induced strain was low and negligible. However, as the gauge cross-sections were reduced by using a ceramic core the plastic strains increased significantly. The introduction of stress concentration features accentuated the accumulated strains. Positioning a notch in the top of the gauge generated the highest strains; TCB bobbin was predicted to have approximately $13 \%$ plastic strain after casting.

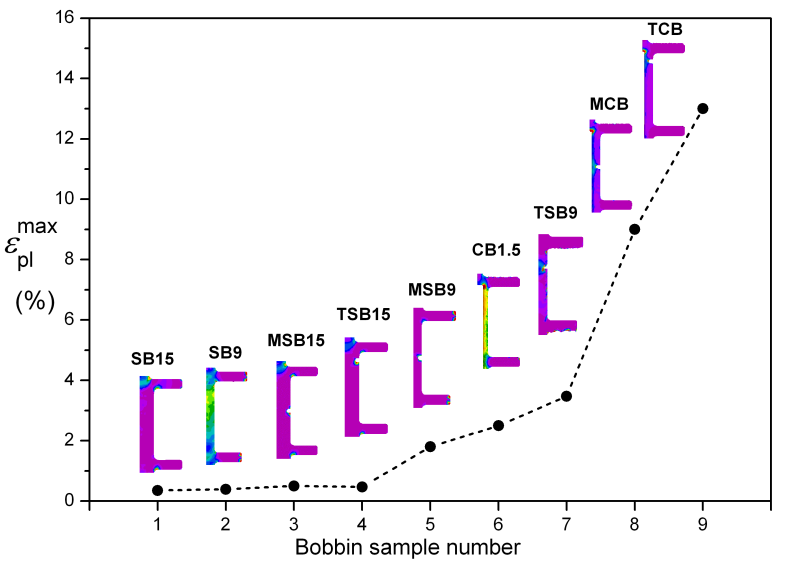

Figure 9: Variation of the predicted plastic strain at ambient temperature for the different geometries at location $L_{3}$.

Comparison with results from casting trials

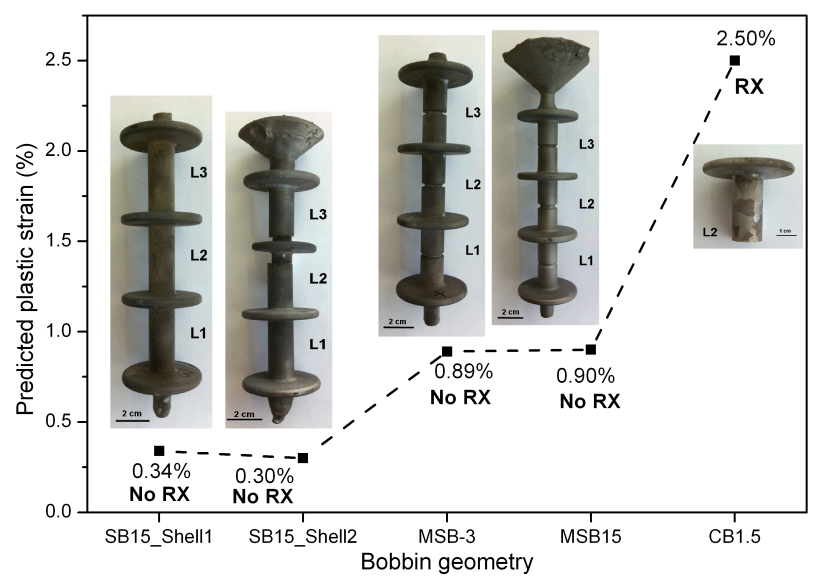

Figure 10: Variation of effective plastic strain predicted in the cast testpieces and associated observations of recrystallisation after solution heat treatment.

In order to assess the accuracy of the modelling, targeted model-driven experimentation was carried out which involved some of the bobbin geometries being cast. The castings fabricated are identified in Figure 10. After subsequent solution heat treatment, none of the solid castings with $15 \mathrm{~mm}$ gauge diameter recrystallised, however when 
the gauge thickness was reduced to $1.5 \mathrm{~mm}$ with a ceramic core recrystallisation was produced over the entire length of the casting, see Figure 11. In Figure 12 the evolution
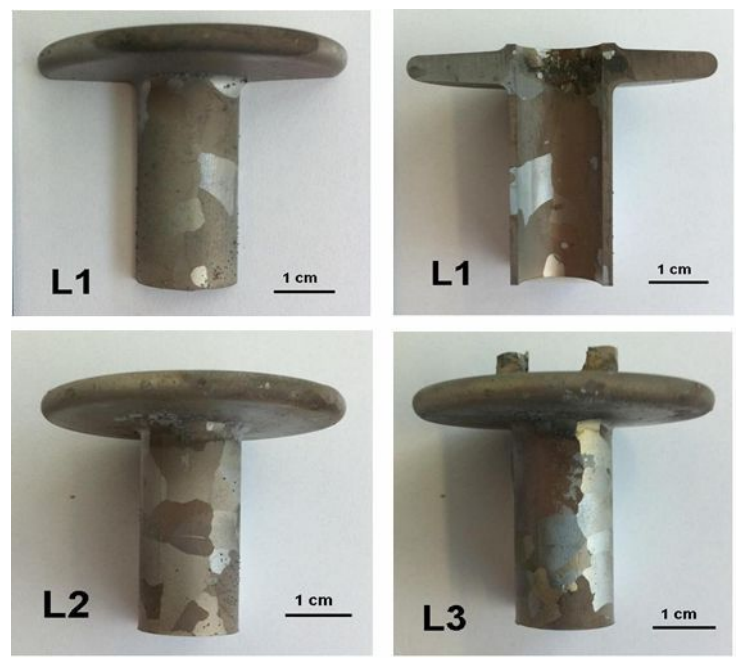

Figure 11: Recrystallisation in cored bobbin CB1.5 after solution heat treatment.

of the plastic strain in the individual gauge sections of the simple solid casting and the cored casting is plotted. During cooling, plastic strain of only $0.35-0.4 \%$ is predicted in the former, and $\sim 2.5 \%$ in the latter. One would expect of course that the recrystallisation would depend upon the nature of the plastic strain. In order to check this, the nature of cooling stresses within the castings was examined in conjunction with the plastic strain level accumualted. Figure 13 compares the distribution of effective plastic strains and average normal stresses on a longitudinal section and the surface of the solid and cored castings.

It was found that the normal stresses within the gauge regions of the castings were primarily tensile, consistent with the lower thermal expansion coefficient of the ceramic mould. The strains within the solid casting were below the critical level to cause recrystallisation, as observed. However, the tensile strains induced within the cored casting were above the critical level, causing the entire casting to recrystallise.

The intensity and distribution of normal stresses increased with the solidification height. This would be expected as the cooling of the lower regions would impart contraction stresses on the regions above which would be at higher temperatures; this is also consistent with the results presented in Figure 6. This, consequently, was

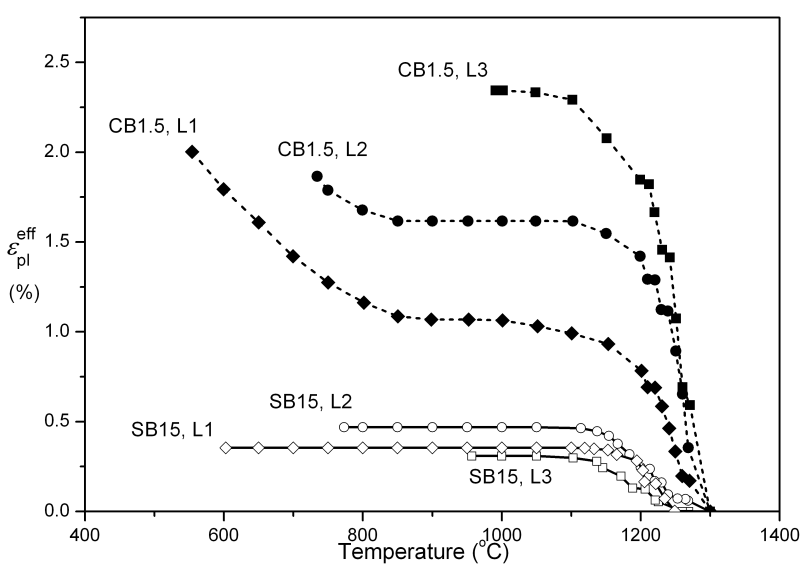

Figure 12: Plastic strain evolution during casting of bobbin testpieces SB15 and CB1.5 at the different locations.

reflected in the strain distribution. Figure 12 showed that during the cooling of the cored casting $L_{3}$ got strained the earliest and $L_{1}$ was the last region to get strained to the maximum. Towards the end of the cooling process all the gauge sections had approximately the same amount of plastic strain.

Moreover, plastic strain in the cored casting was higher on the inner surface than the outer surface; on the other hand, the normal stresses were lower on the inner surface than on the outer surface. The fillet regions between the flanges and the gauges in the cored casting did not show any particular stress concentration (except a thin region showing compressive stresses in the fillet region below $L_{1}$ ); consequently, this generated no strain in these regions. However, stress concentration was observed in the fillet regions of the solid casting; it was primarily tensile in nature, however the fillet region below $L_{1}$ showed compressive stresses also. In the cored casting the ratio of the gauge cross-section to the flange thickness is much smaller than in the solid casting. Hence, in the cored casting the gauge regions are most susceptible to developing the very highest plastic strains $(\sim 2.5 \%)$. On the other hand, in the solid casting, strains get concentrated on features such as fillet regions, and the gauge regions develop only half the maximum strain at most $(\leq 0.15 \%)$. In the solid casting, strain concentration was only observed in the fillet regions which were below the flanges due to the effect of axial contraction during the cooling. In both castings, the gauge regions closer to the flanges displayed higher normal stresses, and consequently higher plastic strains. In the 


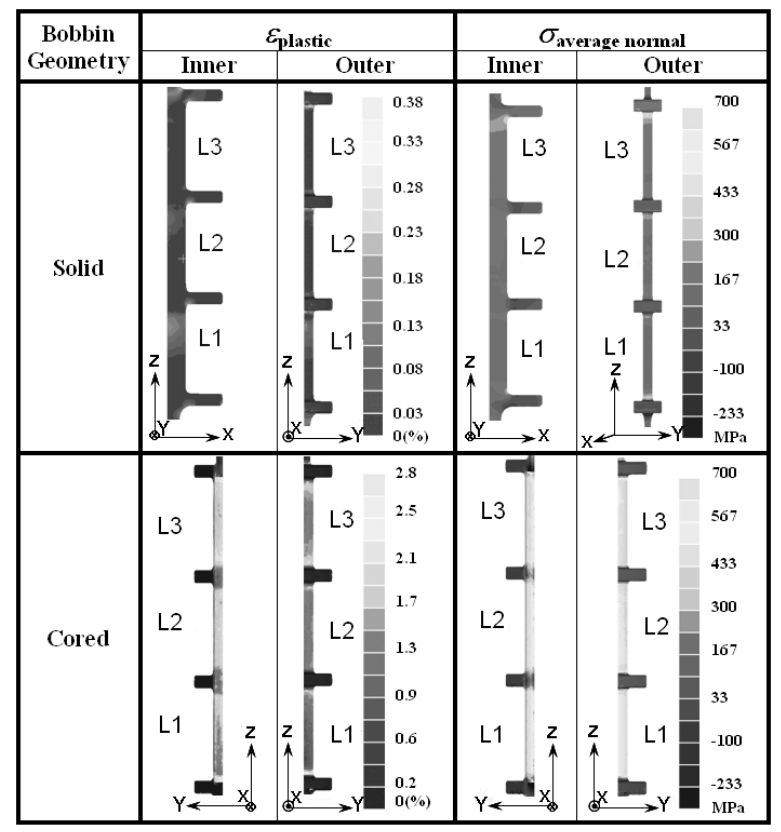

Figure 13: Distribution of effective plastic strains and average normal stresses in the solid and cored testpieces on completion of the casting (30 degree sections).

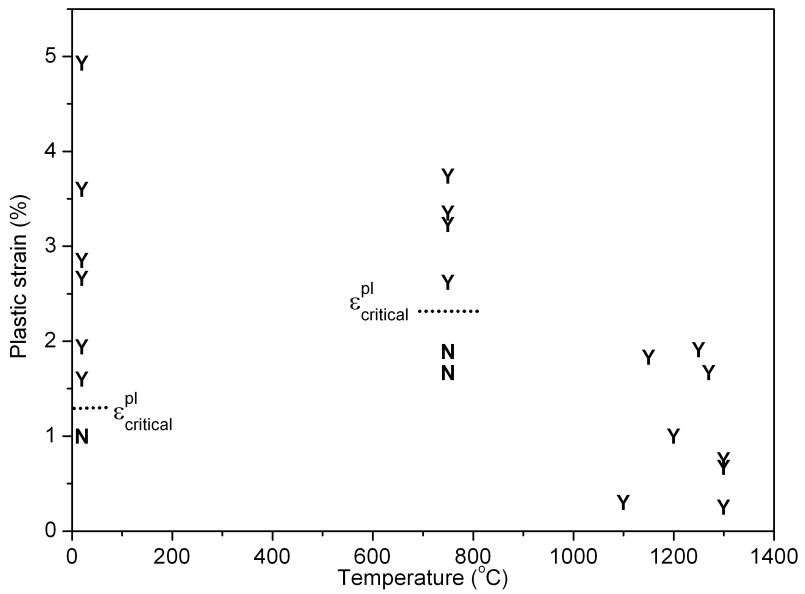

Figure 14: Recrystallisation results for CMSX-4 after uniaxial compression; all samples were solution heat treated after straining. The label ' $\mathrm{N}$ ' means no recrystallisation and ' $\mathrm{Y}$ ' means recrystallisation occurred. cored casting, the middle two flanges showed local compressive stresses at the interfaces with the gauge regions. These developed $0.5-1 \%$ plastic strains, and according to Figure 14 such regions could have been additional sites for nucleation of recrystallisation.

As a final check of the conclusions drawn from this work, cylindrical compression testpieces of CMSX-4 in the as-cast condition were deformed to various levels of plastic strain, at temperatures between 1100 and $1300^{\circ} \mathrm{C}$, $750^{\circ} \mathrm{C}$ and ambient conditions; they were then subjected to the standard solutioning heat treatment to determine whether recrystallisation occurred. The compression testpieces were sliced from cylindical cast bars and therefore recrystallisation tended to occur preferentially at the ascast surfaces [6]. The results are summarised in Figure 14. The critical plastic strains for recrystallisation were found to be $1-1.5 \%$ and $2-2.5 \%$ at $20^{\circ} \mathrm{C}$ and $750^{\circ} \mathrm{C}$, respectively, but at $1100^{\circ} \mathrm{C}$ or higher the critical value was $<0.3 \%$. Our analysis indicates that some low levels of strain can be readily accumulated in investment castings, particularly around stress concentration features, in thin-walled castings and with shells which are stiff. 


\section{Summary and Conclusions}

A model for the analysis of processing-induced plasticity during investment casting has been presented. It is capable of predicting the sites of localised plasticity needed for recrystallisation to occur during heat treatment of single crystal castings. The specific conclusions are:

- The analysis suggests that the plasticity needed for recrystallisation is likely to be induced during the early stages of cooling, when the temperature remains above $1000^{\circ} \mathrm{C}$. This is supported by metallurgical evidence via TEM observations, which indicate that the dislocations are present as networks at the $\gamma / \gamma^{\prime}$ interfaces, rather than shear bands which penetrate the $\gamma^{\prime}$ precipitates.

- The modelling and supporting experimentation indicate that recrystallisation is exacerbated by stiffer and thicker shells, by reduced metallic cross-sections and in particular by the presence of stress concentration features. For many of the processing conditions considered - for example thicker plain cylindrical geometries - the induced plastic strain was insufficient to cause recrystallisation.

- Recrystallisation was reproduced successfully in laboratory-scale cored castings of CMSX-4 of wall thickness $1.5 \mathrm{~mm}$, for which the modelling indicated that the total plastic strain accumulated during cooling to ambient temperature was $\sim 2.5 \%$. Castings of greater wall thickness were not prone to recrystallisation.

- Recrystallisation was reproduced successfully in compression testpieces subjected to deformation at elevated temperatures. Plastic deformation of less than $\sim 0.3 \%$ in the range $1100^{\circ} \mathrm{C}$ and $1300^{\circ} \mathrm{C}$ was sufficient to cause recrystallisation. Deformation at $20^{\circ} \mathrm{C}$ and $750^{\circ} \mathrm{C}$ required substantially greater deformation of $1.5 \%$ and $2.5 \%$, respectively, or more.

- With further development, such modelling will aid turbine blade designers to assess the casting strains induced around intricate features, such as blade cooling holes and fillets, and thus to set design criteria to avoid recrystallisation in investment cast blades.

\section{Acknowledgments}

Two of the authors, Chinnapat Panwisawas and Harshal Mathur, acknowledge support from the Engineering \& Physical Sciences Research Council (EPSRC) and RollsRoyce plc, in the form of Dorothy Hodgkin Postgraduate
Awards (DHPAs). Helpful discussions with Paul Brown and Neil Jones of Rolls-Royce plc are acknowledged. The provision of the ProCAST software by the ESI Group - and the help of Dr Rajab Said in organising this - is acknowledged as part of the PRISM $^{2}$ collaboration at the University of Birmingham.

\section{References}

[1] D.C. Cox, B. Roebuck, C.M.F. Rae, and R.C. Reed. Recrystallisation of single crystal superalloy CMSX-4. Materials Science and Technology, 19:440-446, 2003.

[2] A.S. Sabau. Alloy shrinkage factors for the investment casting process. Metallurgical and Materials Transactions B, 37B:131694, 2006.

[3] R.C. Reed. The Superalloys: Fundamentals and Applications Cambridge: Cambridge University Press, 2006.

[4] J. Meng, T. Jin, X. Sun, and Z. Hu. Effect of surface recrystallization on the creep rupture properties of a nickel-base single crystal superalloy. Materials Science and Engineering A, 527:6119-6122, 2010 .

[5] D. Goldschmidt, U. Paul, and P.R. Sahm. Porosity clusters and recrystallization in single-crystal components. Proceedings of "Superalloys 1992" conference (ed. S.D. Antolovich et al.), Seven Springs, Pennsylvania, TMS, pages 155-164, 1992.

[6] R. Burgel, P.D. Portella, and J. Preuhs. Recrystallization in single crystals of nickel base superalloys. Proceedings of "Superalloys 2000" conference (ed. T.M. Pollock et al.), Seven Springs, Pennsylvania, TMS, pages 229-238, 2000.

[7] S.D. Bond and J.W. Martin. Surface recrystallization in a single crystal nickel-based superalloy. Journal of Materials Science, 19:3867-3872, 1984

[8] L. Wang, F. Pyczak, J. Zhang, L.H. Lou, and R.F. Singer. Effect of eutectics on plastic deformation and subsequent recrystallization in the single crystal nickel base superalloy CMSX-4. Materials Science and Engineering A, 532:487-492, 2012.

[9] C.-Y. Jo, H.-Y. Cho, and H.-M. Kim. Effect of recrystallisation on microstructural evolution and mechanical properties of single crystal nickel base superalloy CMSX-2: Part 1 - microstructural evolution during recrystallisation of single crystal. Materials Science and Technology, 19(12):1665-1670, 2003.

[10] T.R. Chandrupatla and A.D. Belegundu. Introduction to Finite Elements in Engineering. New Jersey: Prentice hall, 1991.

[11] S.V. Nair and K. Jakus. High temperature mechanical behavior of ceramic composites. Boston: Butterworth-Heinemann, 1995.

[12] C. Panwisawas, J. Gebelin, N. Warnken, R.W. Broomfield, and R.C. Reed. Numerical modelling of stress and strain evolution during solidification of a single crystal superalloy. Advanced Materials Research, 278:204-209, July 2011. 